\title{
Review Paper \\ Comparison of the Mechanical Effects of Silver Nanoparticles on Some Types of Organisms
}

\section{Seyyedeh Mahbouube Mousavi" ${ }^{1}$ (1), "Nooshin Naghsh² (1)}

1. Department of Biotechnology, Falavarjan Branch, Islamic Azad University, Isfahan, Iran.

2. Department of Biology, Falavarjan Branch, Islamic Azad University, Isfahan, Iran.

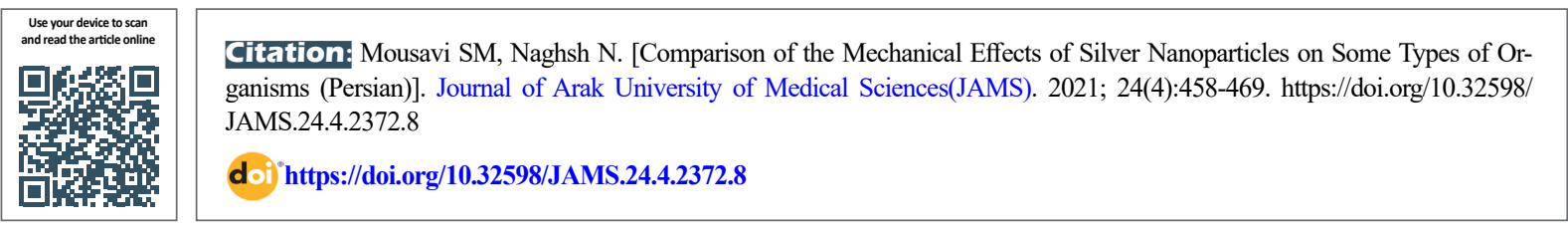

\section{(i) (3)}

Article Info:

Received: 12 Mar 2021

Accepted: 27 Jul 2021

Available Online: 01 Oct 2021

Keywords:

Bacteria, Fungi, Silver

nanoparticles and

antimicrobials

\section{ABSTRACT}

Background and Aim One of the new technologies in this century is nanotechnology. Nanotechnology is a vast and promising research platform that has opened up a wide range of opportunities in various fields including pharmacy, medicine, electronics and agriculture. One of the applied nanoparticles in the field of nanobiotechnology is silver nanoparticles. One of the most important features of these nanoparticles is the creation of programmed cell death (Apoptosis). This property has created its antiseptic properties against bacteria, fungi, viruses and nematodes. Nanoparticles have better performance against microorganisms due to their high surface-to-volume ratio and higher contact surface. Meanwhile, silver nanoparticles have shown unparalleled antimicrobial activity against a wide range of microorganisms and have recently attracted the attention of many researchers.

Methods \& Materials In this study, a review of all databases, including ISI Web of Science, Scopus, ISC, PubMed, Google Scholar Learners, Noor, related articles were examined.

Ethical Considerations Ethical principles have been observed in writing the article.

Results The antimicrobial effect of silver nanoparticles depends on the concentration, shape and diameter of the nanoparticles as well as the time of effect and the type of microorganism. The molecular mechanism of these nanoparticles has been through oxidative stress. The mechanism of inhibitory action of silver ions on microorganisms is the loss of DNA replication ability, inactivation of the expression of ribosomal subunit proteins and other bacterial cell proteins and enzymes necessary for ATP production. The effect of silver ions is primarily on the function of membrane-bound enzymes such as key enzymes in the respiratory chain. Thus, similar cellular mechanisms can cause cell death effects in prokaryotes, fungi, and eukaryotes.

Conclusion The results showed that variables such as type of microorganism, contact time, concentration, shape and diameter of silver nanoparticles had a significant effect on inhibiting microbial growth.

\section{Extended Abstract}

\section{Introduction}

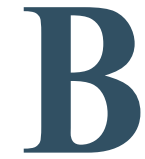

Nanotechnology recognizes, produces, and applies materials in dimensions smaller than 1000 nanometers at the atomic, molecular, and macromolecular scales [1]. Silver nanoparticles are clusters of silver atoms that range from 1 to 100 nanometers. The properties of nano-sized silver are very different from the properties of this element in bulk size. Silver nanoparticles' physical, optical, thermal, chemical, electrical, mechanical, and biological properties are unique [2]. Using nano-silver with different

* Corresponding Author:

Nooshin Naghsh, PhD.

Address: Department of Biology, Falavarjan Branch, Islamic Azad University, Isfahan, Iran.

Tel: +98 (913) 2009276

E-mail: n_naghsh@yahoo.com 

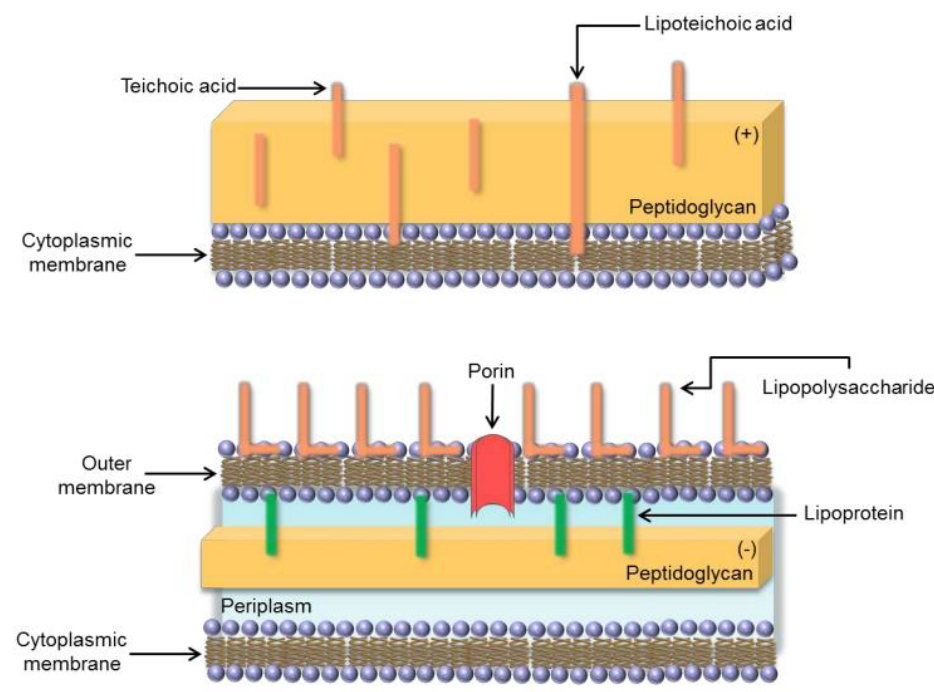

Figure 1. Cell wall differences in gram (-) and gram (+) bacteria

materials such as fibers, dyes, polymers, ceramics enables us to produce products that make our environment free of germs while not harming the environment [1]. Therefore, this review article aimed to summarize the antimicrobial application mechanisms of silver nanoparticles in different shapes, sizes, and concentrations on the cells of other organisms.

\section{Materials \& Methods}

PubMed, ISI, Web of Science, Scopus, ISC, and Google Scholar databases were used to collect and summarize data. Research papers using the MeSH model were: fungi, viruses, bacteria, and antimicrobial properties of silver nanoparticles. Ethical considerations: Ethical principles in writing the article are per the instructions of the National Ethics Committee and the COPE regulations.

\section{Result}

The antimicrobial effect of silver nanoparticles depends on the concentration, shape, and diameter of the nanoparticles, as well as the time of impact and the type of microorganism. The molecular mechanism of these nanoparticles has been through oxidative stress. The mechanism of inhibitory action of silver ions on microorganisms is the loss of DNA replication ability inactivation of the expression of ribosomal subunit proteins and other bacterial cell proteins and enzymes necessary for ATP production. The effect of silver ions is primarily on the function of

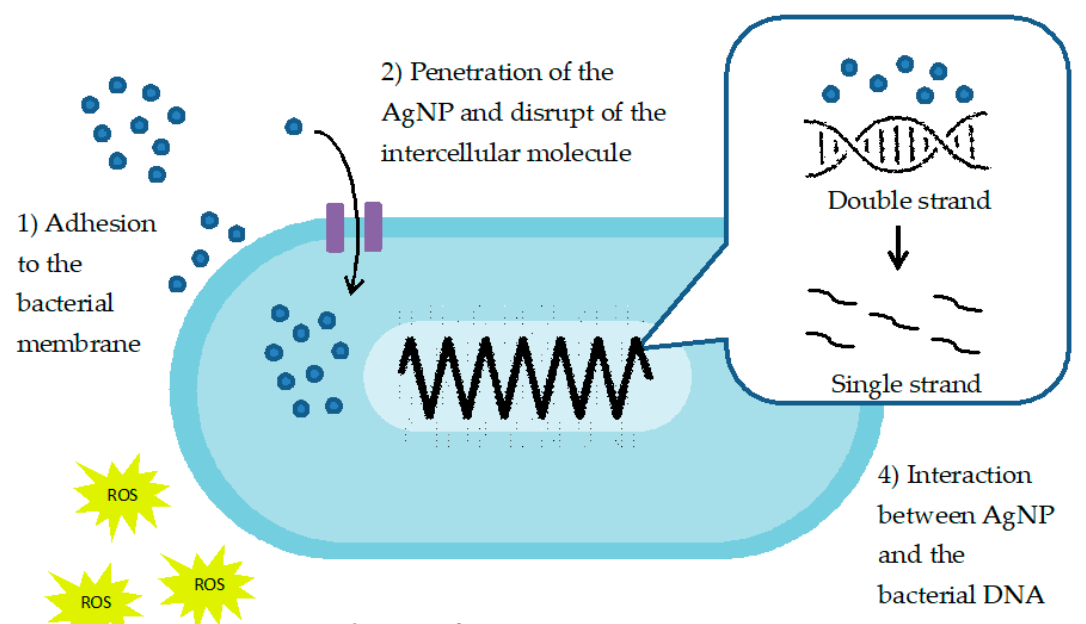

3) Production of ROS

Figure 2. The antibacterial activities of silver nanoparticles [9] 
membrane-bound enzymes such as critical enzymes in the respiratory chain. Thus, similar cellular mechanisms can cause death in prokaryotes, fungi, and eukaryotes.

\section{Discussion \& Conclusion}

Using silver nanoparticles as a new antimicrobial agent has recently attracted the attention of many researchers. Researchers have proven the ability of silver nanoparticles to fight spoilage and pathogenic microorganisms. Numerous studies were conducted on possible reactions between the nanoparticles and macromolecules of living organisms. The difference between the negative charge of the microorganism and the positive charge of the nanoparticle acts by creating adsorbent electromagnetic bands between the microbe and the nanoparticle, causing the nanoparticle to attach to the cell surface, resulting in cell death. Eventually, many of these contacts lead to the oxidation of the surface molecules of the microbes and their rapid extinction. The ions released from the nanomaterials are likely to react with the thiol groups of SH surface proteins of bacterial cells. Some of these bacterial cell membrane proteins transport minerals from the wall surface. Nanomaterials cause inactivation and impermeability of cell membranes by acting on these proteins. The loss of membrane permeability eventually leads to cell death. The presence of silver and sulfur ions in compact electron granules in the bacterial cytoplasm after treatment with silver nanoparticles has been observed, which indicates interaction with nucleic acids and leads to disruption of DNA molecule amplification. Nanomaterials also delay bacterial cell adhesion and biofilm formation, which prevents a group of bacteria from stabilizing and multiplying. Silver nanoparticles have antimicrobial properties on most microorganisms, so it can be said that variables, such as the type of microorganism, contact time, concentration, shape, and diameter of silver nanoparticles, factors affecting the occurrence of apoptosis in different types of cells, including prokaryotes and fungi, eukaryotes, and viruses. Considering the biocompatibility of these nanoparticles in specific diameters and concentrations and the reduction of side effects, they can be used as alternatives to standard drugs, such as some antibiotics and antifungals, shortly.

\section{Ethical Considerations}

\section{Compliance with ethical guidelines}

Ethical principles have been observed in writing the article.

\section{Funding}

This article has no financial support.

\section{Authors' contributions}

Both authors contributed to the review and writing of the article.

\section{Conflicts of interest}

The authors declared no conflict of interest.

\section{Acknowledgements}

We would like to thank all the researchers and authors of the articles whose research results were used in this study. 
مقايسه ثأثير ات مكانيسمى نائو ذرات نقره روى برخى از انواع موجودات زنده

سيده محبوبه موسوى' (1)، "نوشين نقش '0

1. أكروه بيوتكنولوزى، واحد فلاورجان، دانشكاه آزاد اسلامي، اصفهان، ايران.

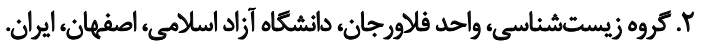

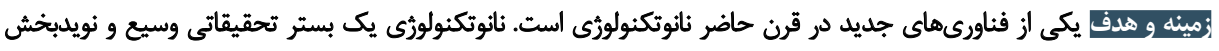

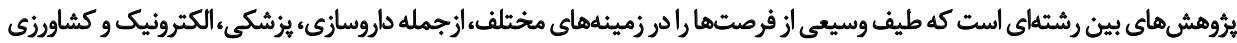

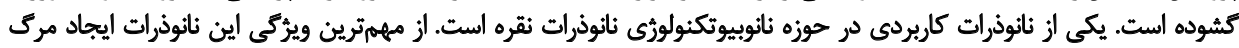

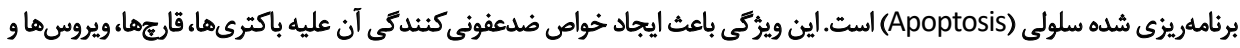

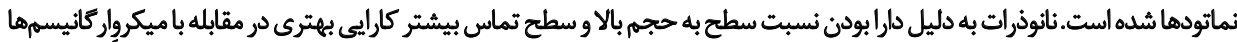

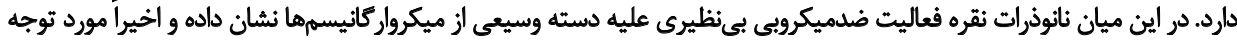

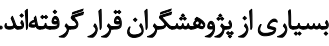

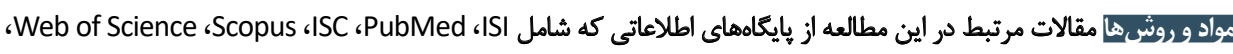
Google Scholar

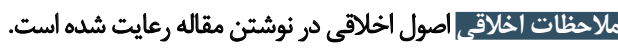

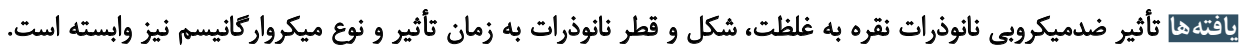

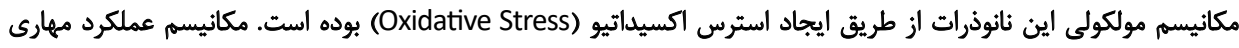

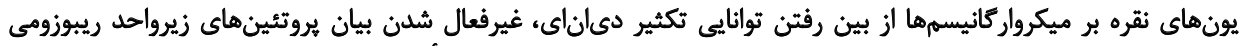

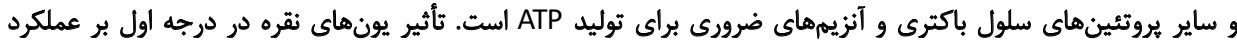

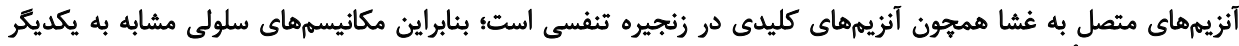

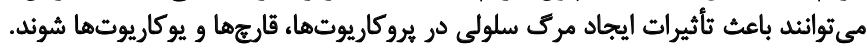

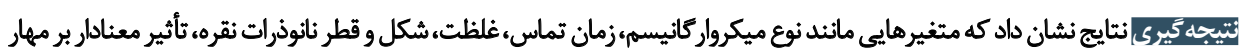

نانوذرات نقره، خوشههايى از اتمهاى نقره هستند كه اندازه

dateo

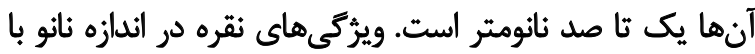

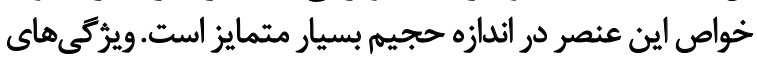

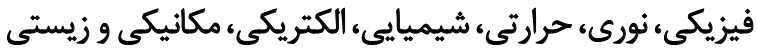

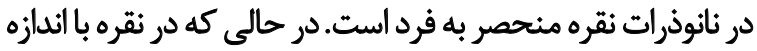

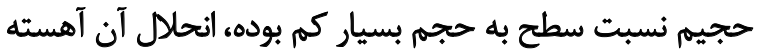

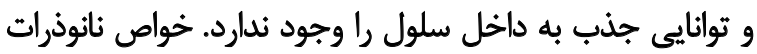

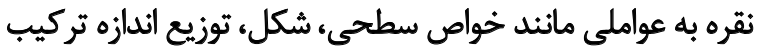

و يوشش ذرات بستّى دارد [r].

استفاده از نائو نقره با مواد مختلف مانئد اليافهاء رنكهاء

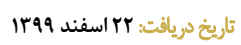

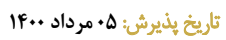

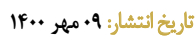

نانوتكنولوزى عبارت از شناخت، توليد و كاربرد مواد در ابعاد

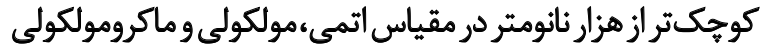

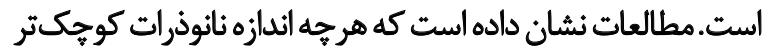

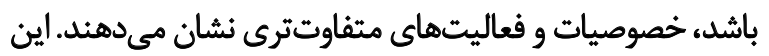

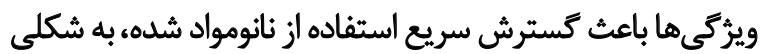

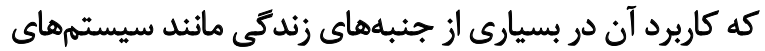
الكترونيكي، كنترل ميكروبي و تشخيص و و درمان بيماريها

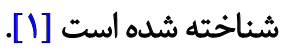

* نويسيده مسئول:

دكتر نوشين نقش نورئد

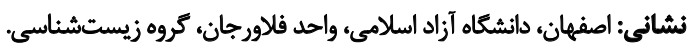

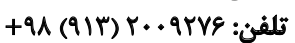

رايانامه: n_naghsh@yahoo.com 
يونهاى نقره مي توانند به كروههاى دهنده الكترون مثل كوكرده،

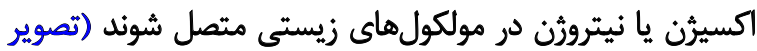

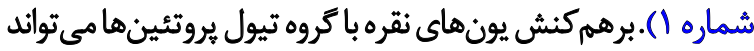

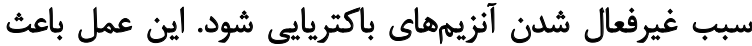

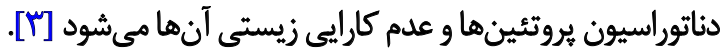
برخى محققان آزادسازى يونهاي نقره را براي اعمال اثر

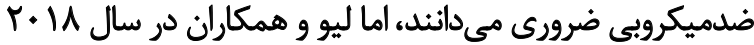

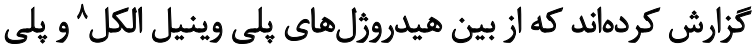

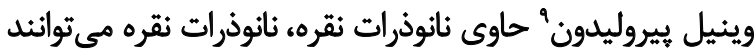

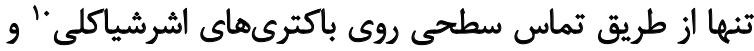

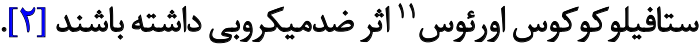

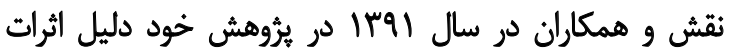

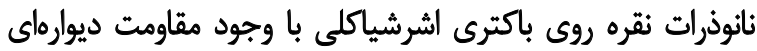

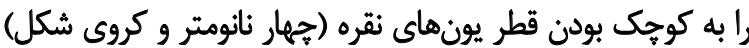

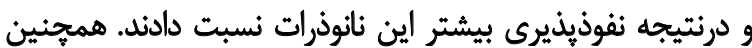

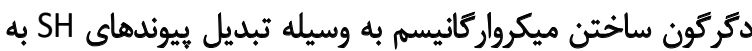

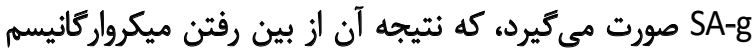

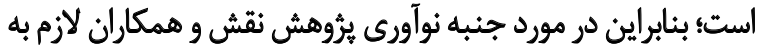

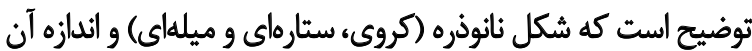

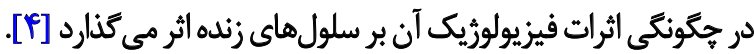

$$
\text { ساغتًار ديواره سلولى باكترىها }
$$

طبق يافتههاي برخي محققان، نانوذرات نقره با اندازه يك تا ده

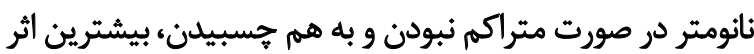

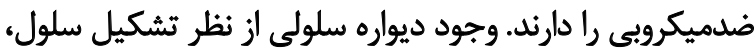

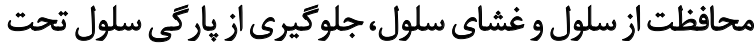

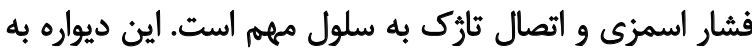

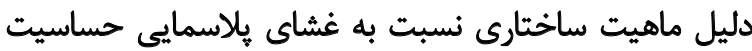

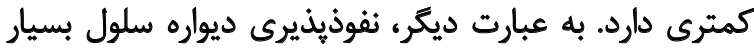

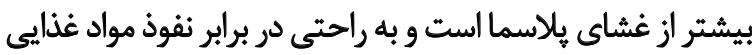

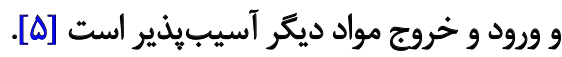
بسته به ساختار،تركيبات و عملكردها، ديواره سلولى، باكترىها

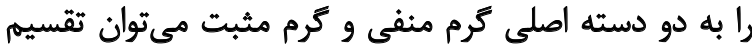

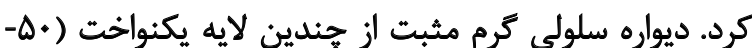

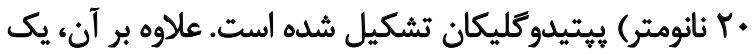

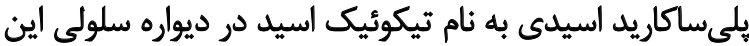

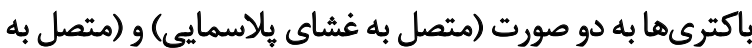

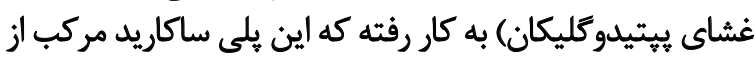

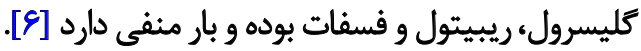

8. Polyvinyl Alcohol

9. Polyvinylpyrrolidone

10. Escherichia Coli

11. Staphylococcus Aureus
بإيمرها و سراميكها ما را قادر ميىسازد محصولى توليد كنيم كه

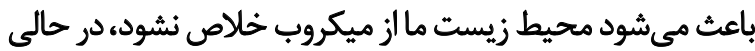

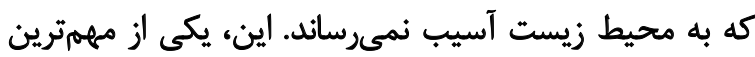
كاربردهاى نانوذرات نقره در يزشكى است استي

يجيشبينى ميشود اين نانوذرات با كنترل فعاليت عوامل

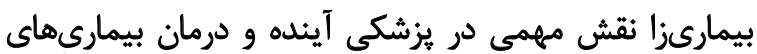

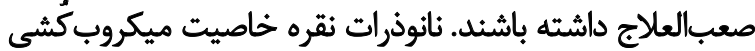

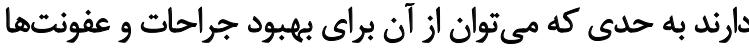

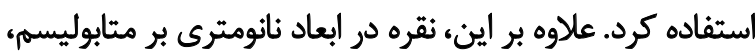

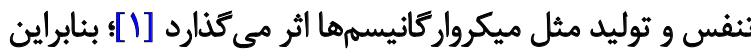

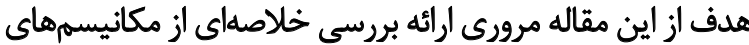

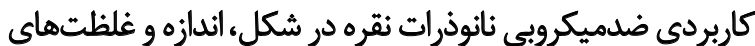
كوناتون روى سلول هاى موجودات مختلف است

مواد و وروُّها تها

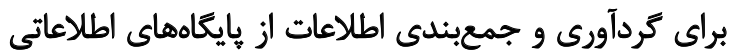

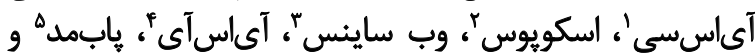

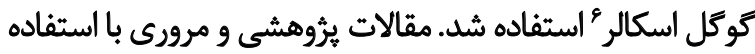

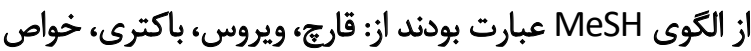

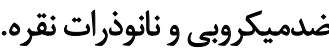

يافتهها تعداد سى مقاله از يايكاههاى اطلاعاتى استخراج و براى نكارش اين مطالعه مرورى استفاده شد.

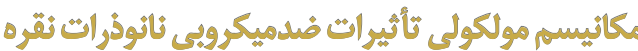

نقره روى طيف وسيعى از ميكروار كانيسمها، مانئد قارجها،

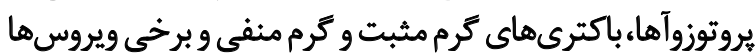

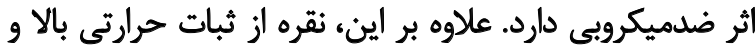

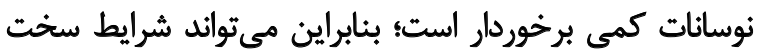

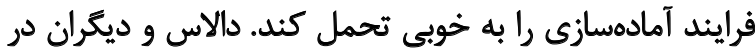

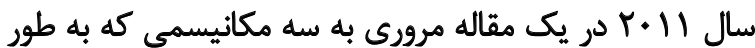

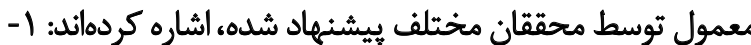

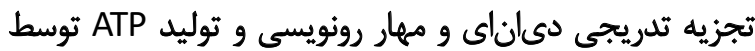

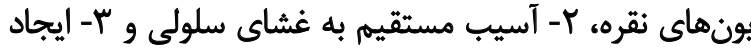

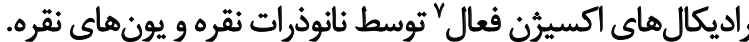

1. ISC

2. Scopus

3. Web of Science

4. ISI

5. Pubmed

6. Google Scholar

7. Reactive Oxygen Species 


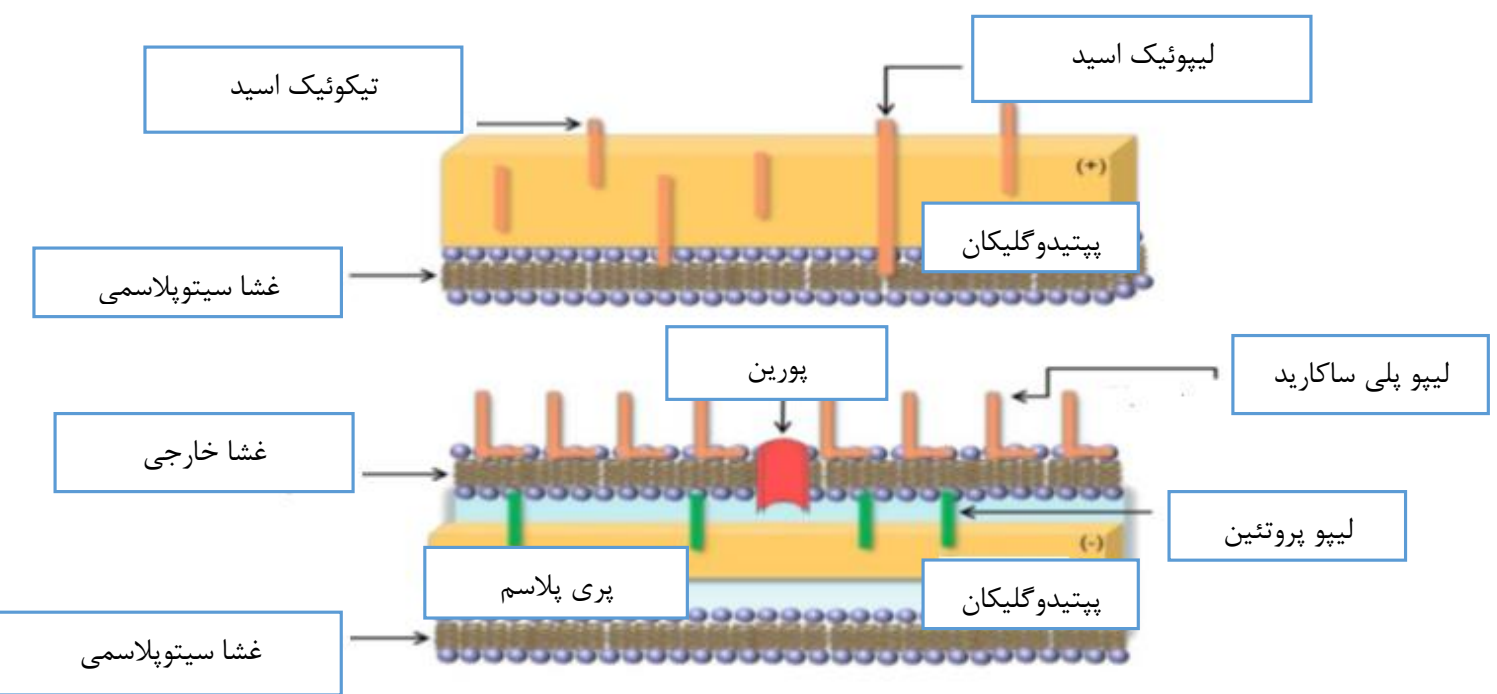

(cins

زمان يونهاى نقره از خود ساطع مى كنيند. اين يونها طى واكنش

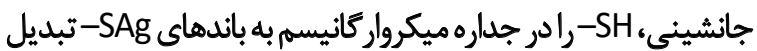

مي كنيد، كه نتيجه واكنش، تخريب ميكرواركانيسم است [VH

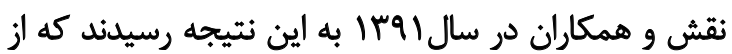

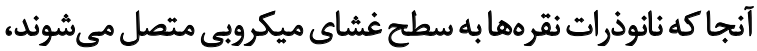

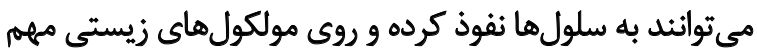

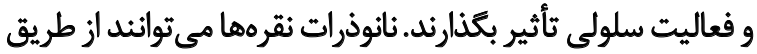

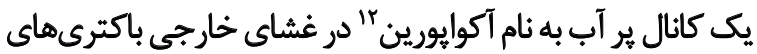

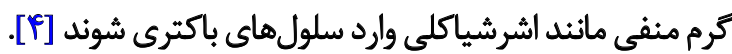
با خس از نفوذ نانوذرات نقرهها به داخل سلولها، اين نانوذرات

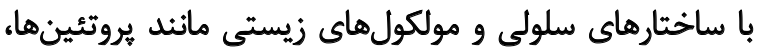

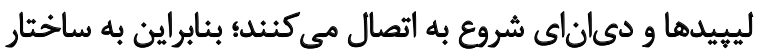

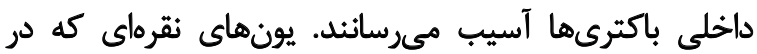

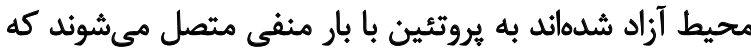

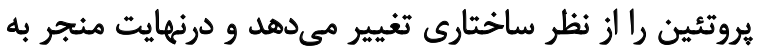

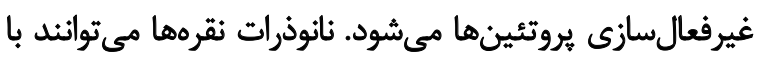

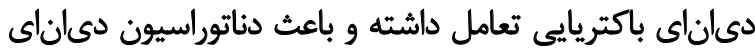
شده و رشد سلولى ميكروبها را راقئ تطع مي كنيند.

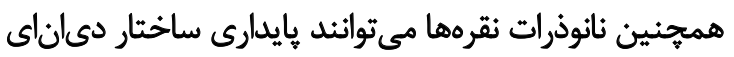

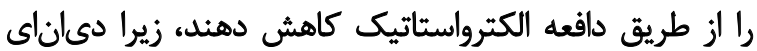

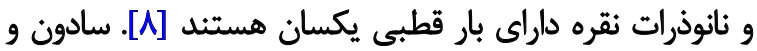

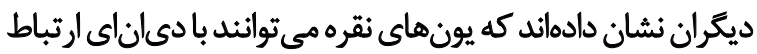

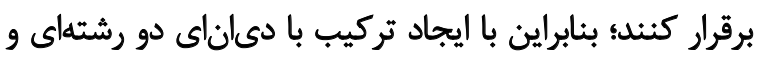

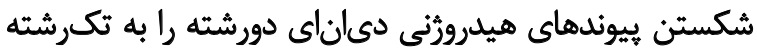

تبديل كنين [9].
تصوير ا. تفاوت ديواره سلولى در باكترىهاى كرم (-) و وكرم (+) [ه] نقش احتمالى نانوذرات نقره در تخريب ديواره سلولى اين

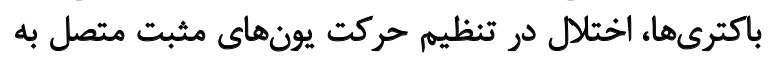

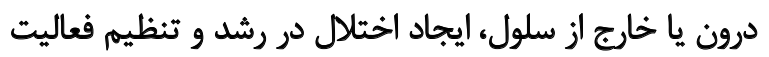

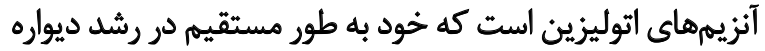

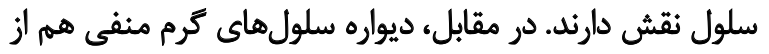

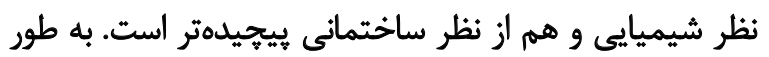

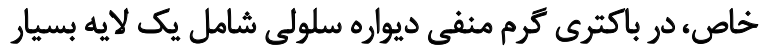

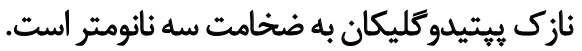

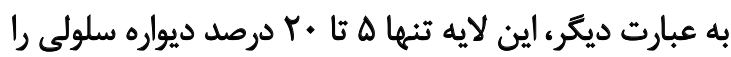

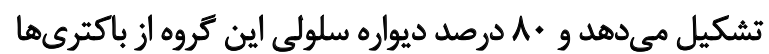

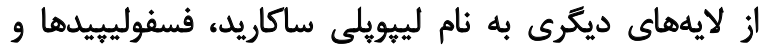

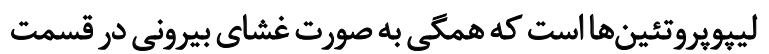

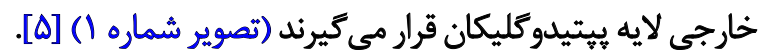
مكاثيسمهاى بيوشيميايع نائوذرات ثقره بر سلول

$$
\text { مكانيسم كاتاليستى }
$$

توليد اكسيثن فعال توسط نقره، اين مكانيسم بيشتر در

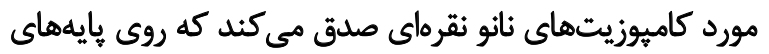

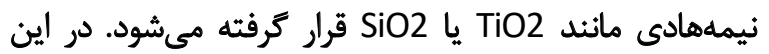

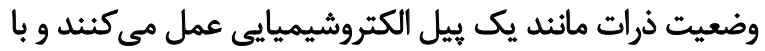

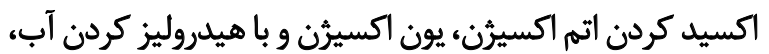

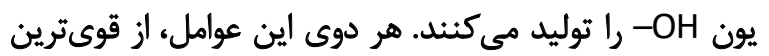
عاملين ضدميكروبى نيز هستند [V]

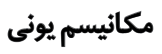

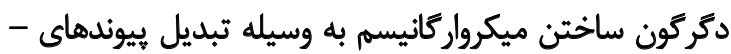

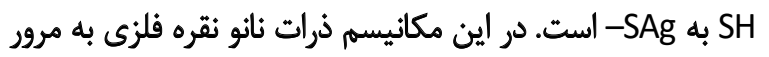




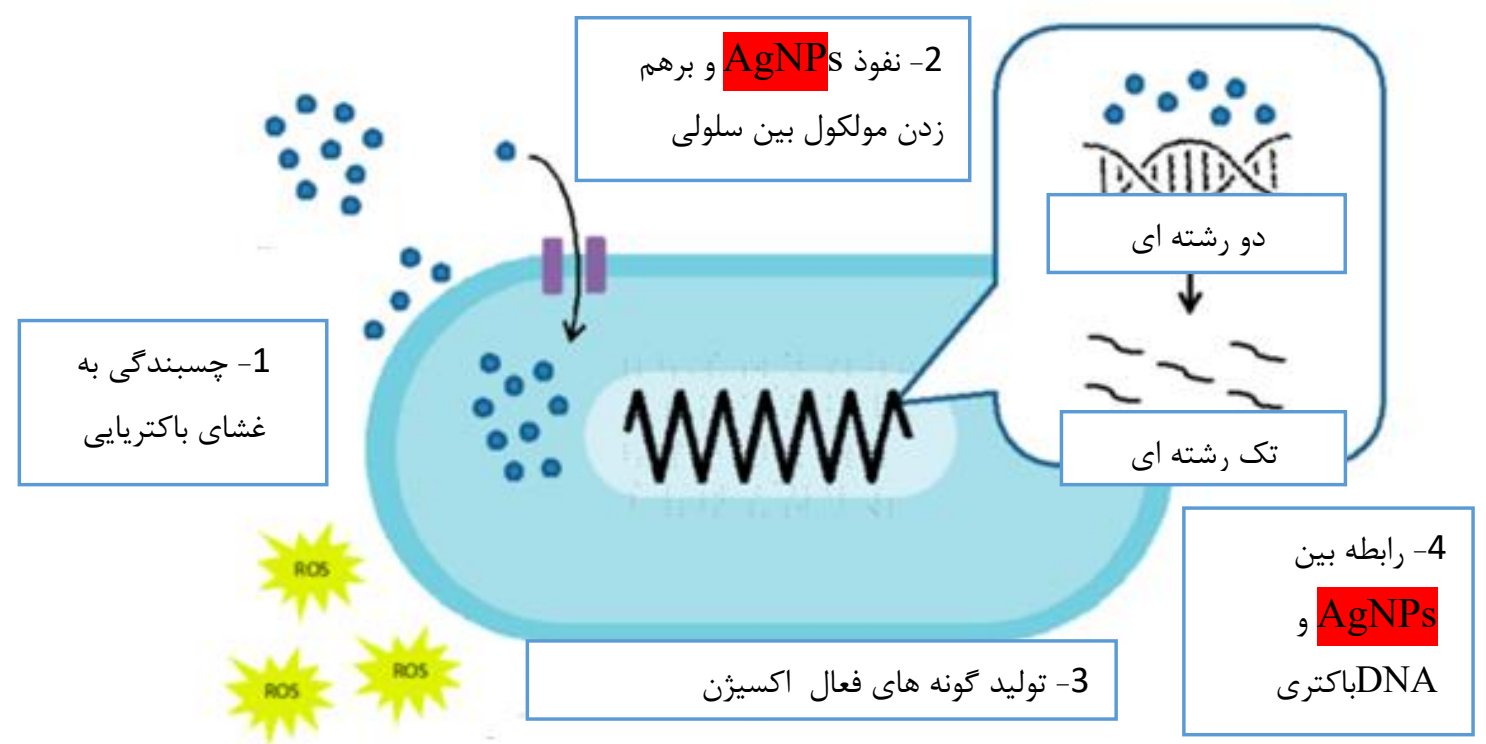

بازدارنده نيز اين نتايج را تأييد كردند. با توجه به اينكه قطر

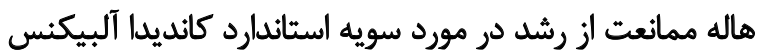
(1677- ATCC)

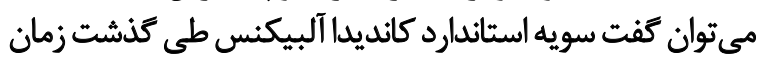

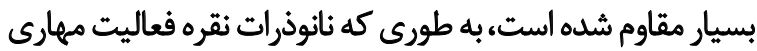

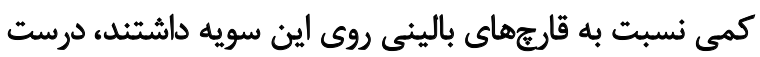

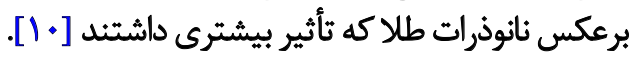

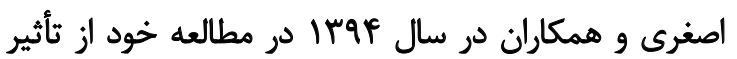

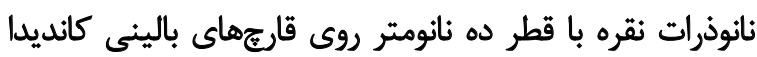

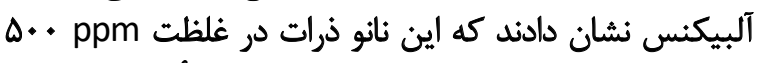

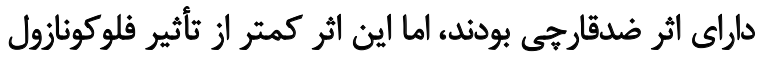

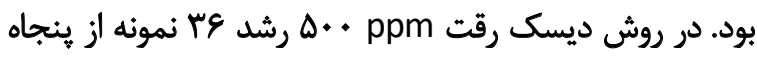

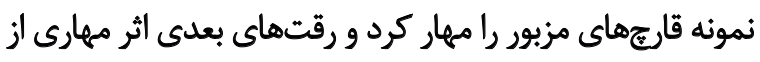

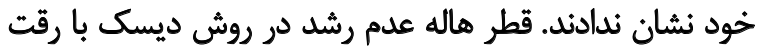

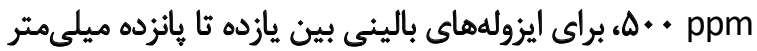

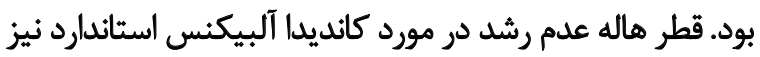

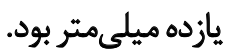
نتايج حاصل از MFC و MIC نيز اين نتايج را تأييد كردند. باتوجه

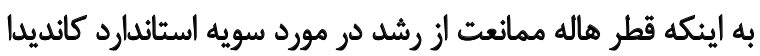

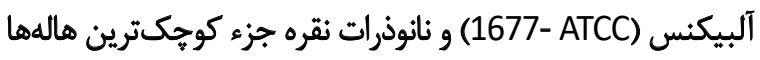

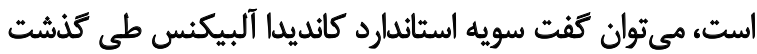

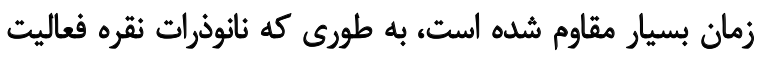

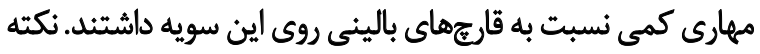

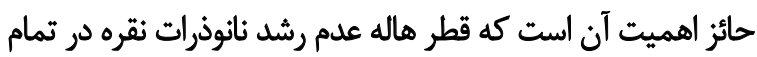

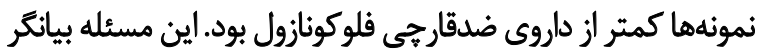

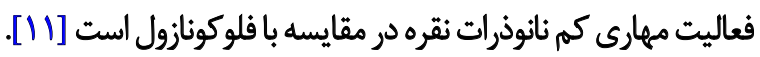

تصوير شماره Y به طور كلى مكانيسم عملكرد نانوذرات نقره إنقات

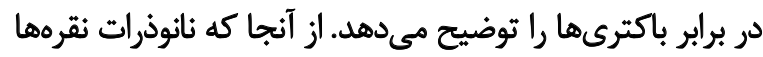

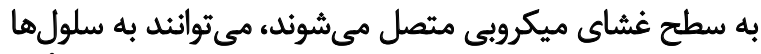

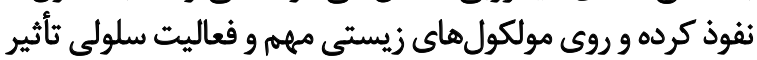

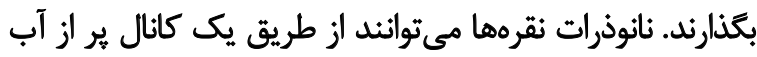

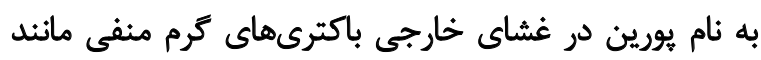

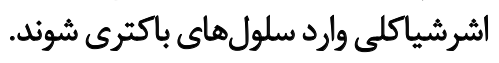

با يس از نفوذ نانوذرات نقرهها به داخل سلولهاء اين نانوذرات

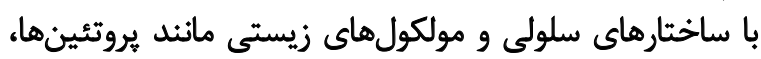

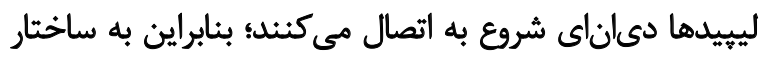

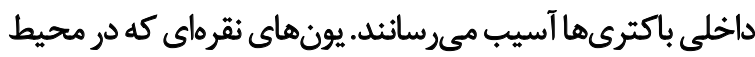

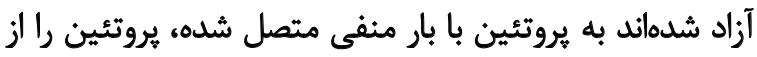

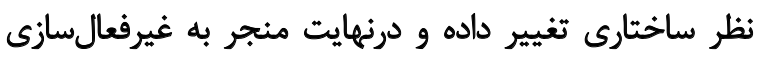

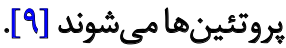
فعاليت ضدميكرويى ثاثوذُرات نثقره فعاليت ضدقارجى

رحيمزاده و همكاران در سال هوجا نشان دادند كه نانوذرات

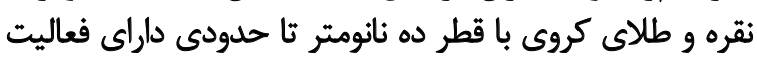

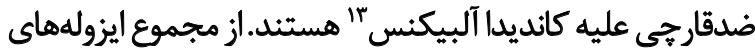

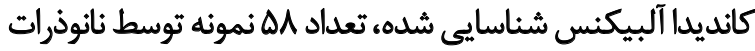

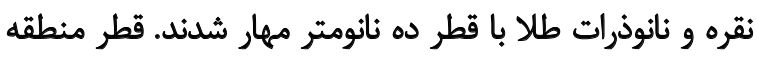

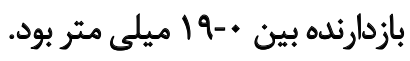

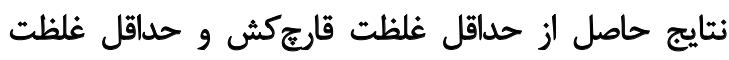

13. Candida Albicans 


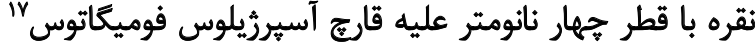

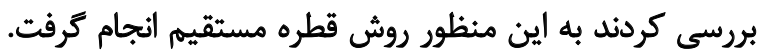

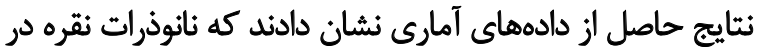

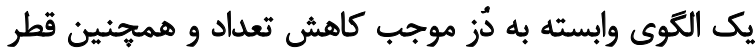

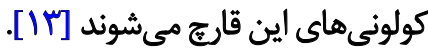

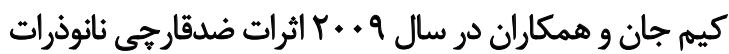

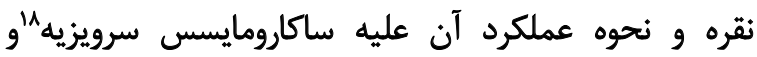

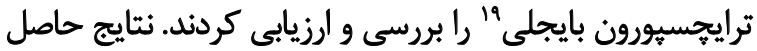

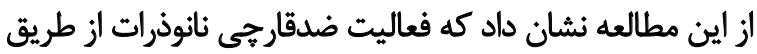

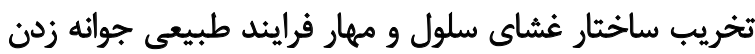

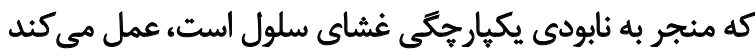

[If]

فعاليت ضدباكتريايى

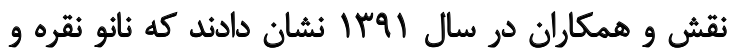

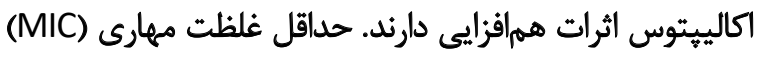

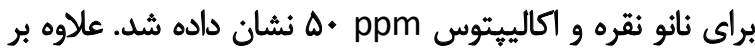

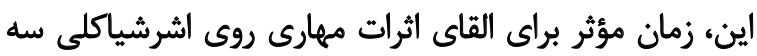

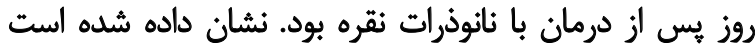

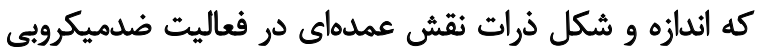

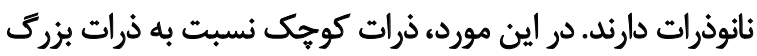

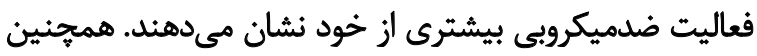

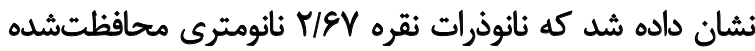

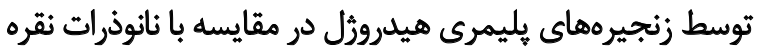

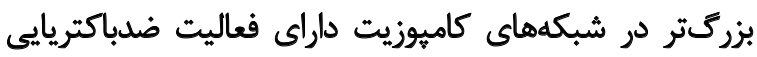

بيشترى هستند [10]

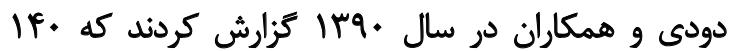

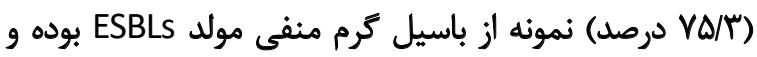

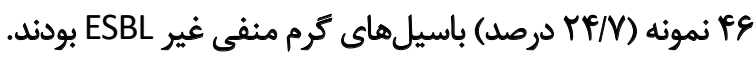

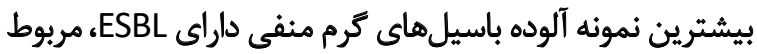

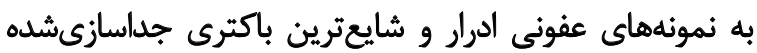
كلبسيلا ينمونيه بَبود.

ppm تمام نمونهها نسبت به محلول نانو ذرات نقره با غلظت

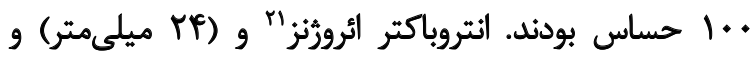

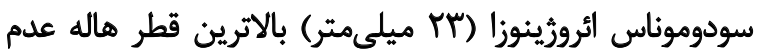

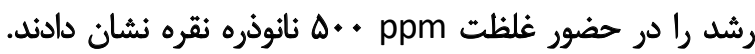

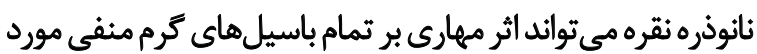

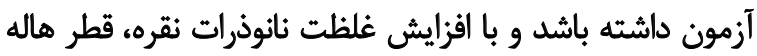

17. Aspergillus Fumigatus

18. Saccharomyce cerevisiae

19. Trichosporon beigelii

20. Klebsiella Pneumoniae

21. Enterobacter Aerogenesis

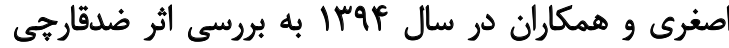

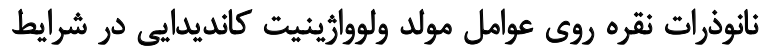

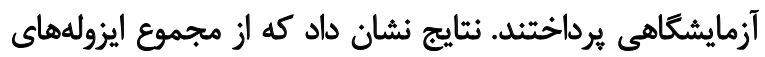

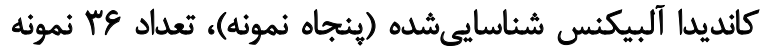

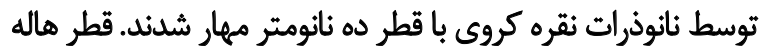

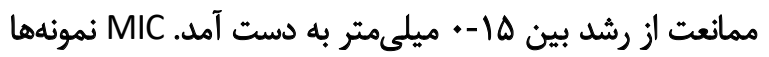

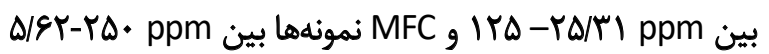

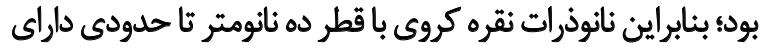

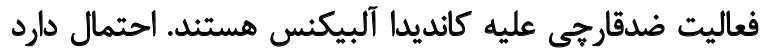

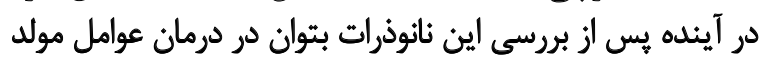
ولووارينيت كانديدايى از آنها استفاده كرد [11]].

نقش و همكاران در سال זوجا نشان دادند كه تعداد

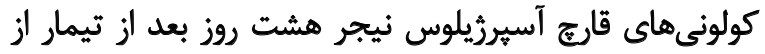

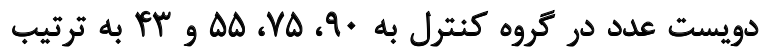

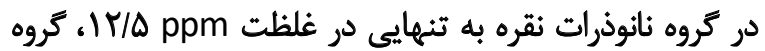

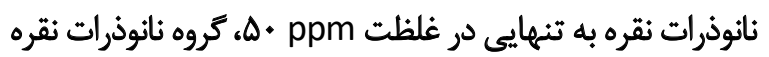

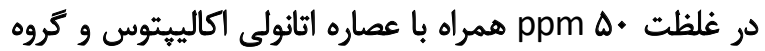

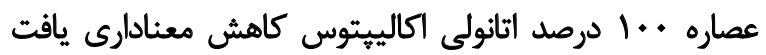

$(P<+1 \cdot \Delta)$

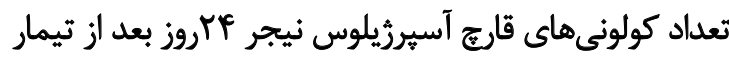

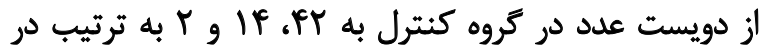

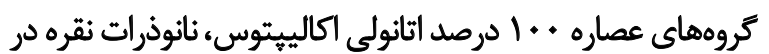

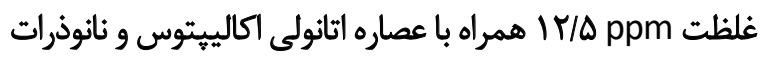

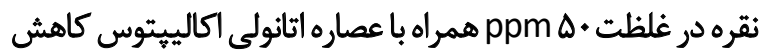

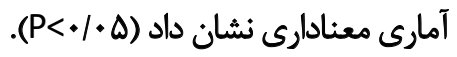

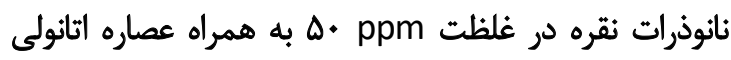

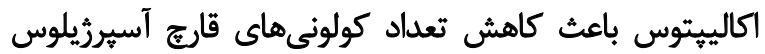

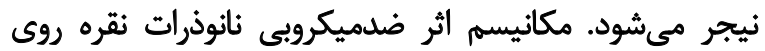

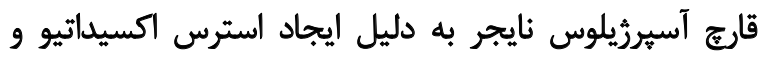

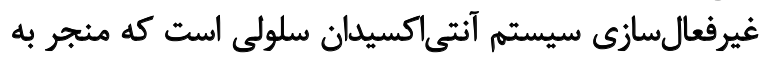

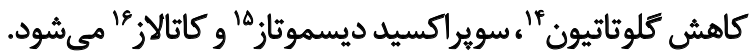
به طور كلى مكانيسمهاى اختصاصى براي اثرات ضدقارجى ني

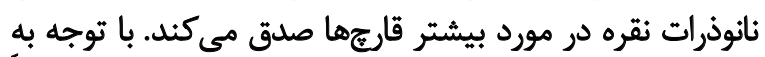

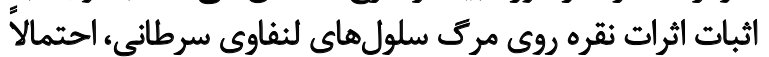

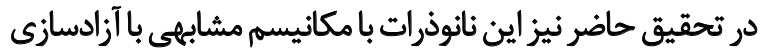

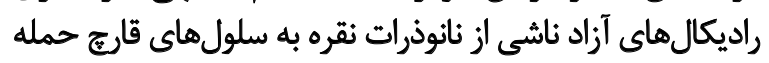

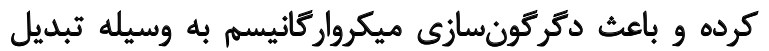
يوندهاى SH به S-Ag شدهاند [IT) نقش و همكاران در سال بوجا اثرات ضدقارجى نانوذرات

14. Glutathione

15. Superoxide Dismutase

16. Catalase 


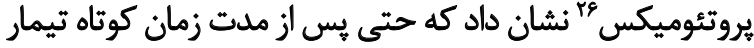

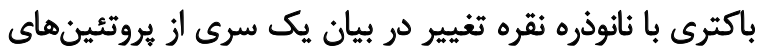

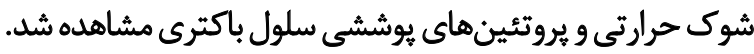

بنابراين اين ذرات مىتوانيد به درون غشا وارد شده و منجر

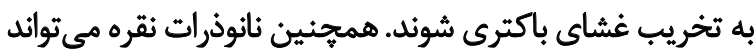

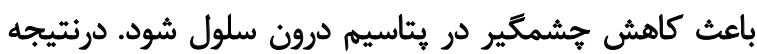

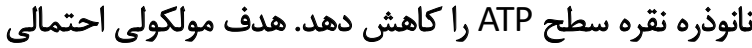

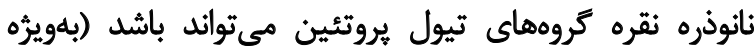

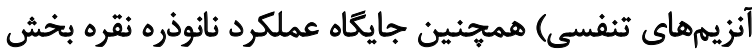

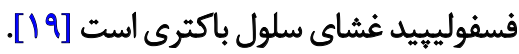

بر اساس تحقيقات انجامشده توسط كيم و همكاران در

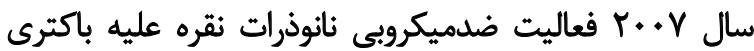

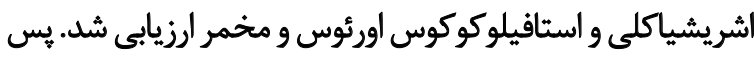

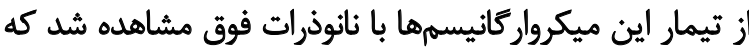

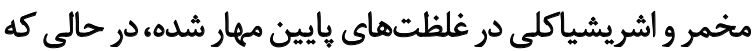

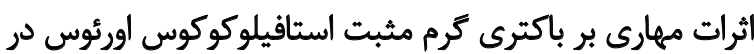

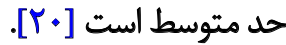

\section{مزاياي ثائوذرات نقره نسبت به آثتى بيوتيكها}

در واقع نانوذرات نقره در مقايسه با آنتىبيوتيكهاى نقره

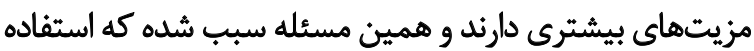

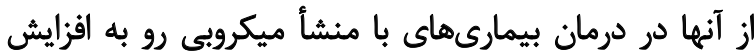

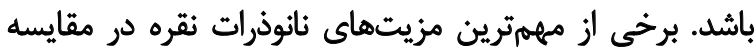

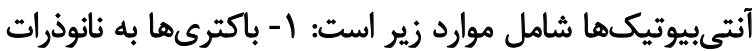

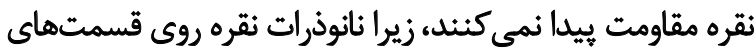

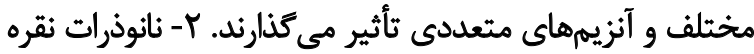

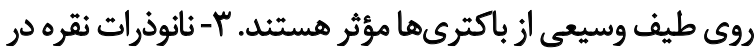

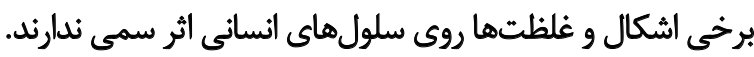

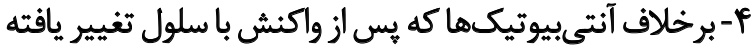

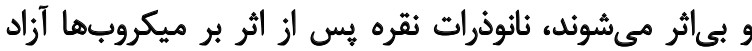

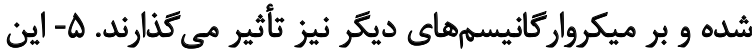

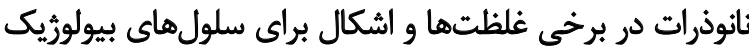

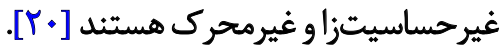

بررسى تأثيرات ثائوذرات ثقره روى بافتهاى مختلف موشهاى

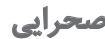

نقش و همكاران در سال |

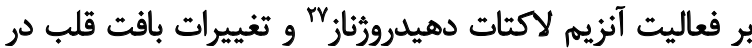

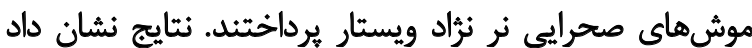

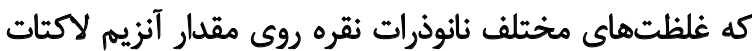

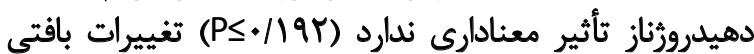

26. Proteomics

27. Lactate Dehydrogenase
عدم رشد باسيل هاى كرم منفى داراي ESBL نيز افزايش مى يابد.

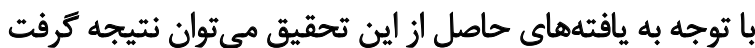

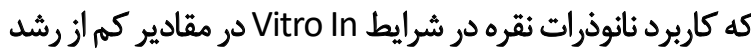

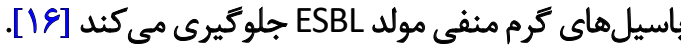
نقش و همكاران در سال بوجا در مطالعه خود مناسبترين

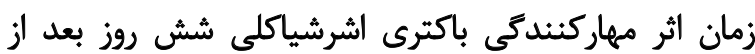

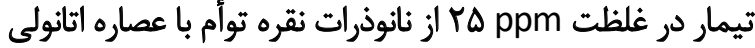

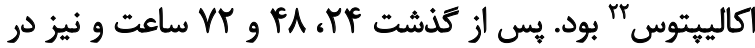

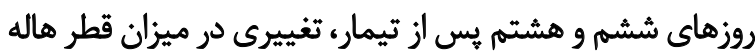

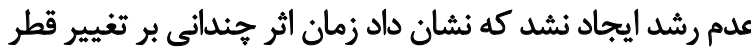

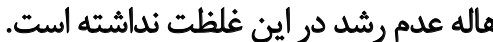

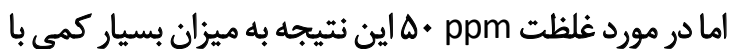

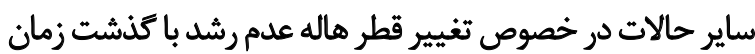

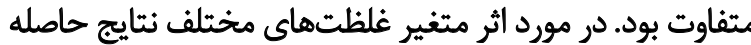

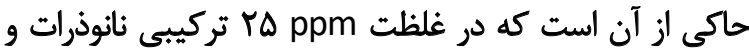

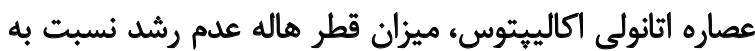

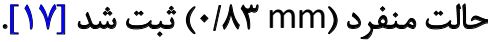

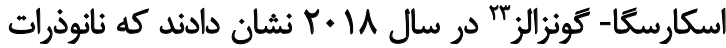

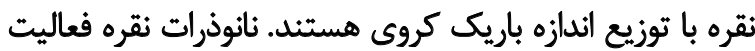

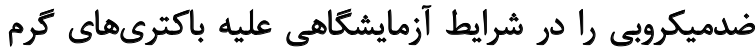

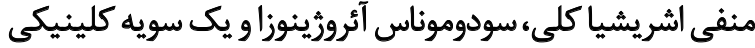

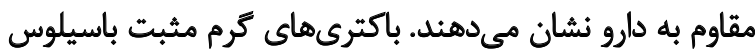

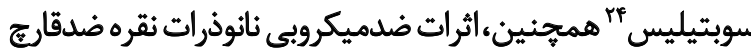

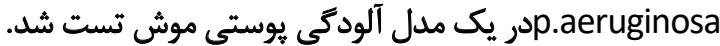
نتايج نشان داد كه نانوذرات نقره كزارش

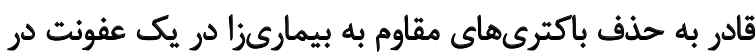

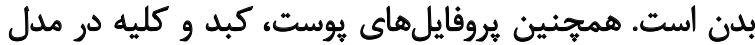

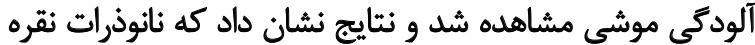

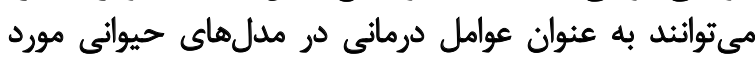

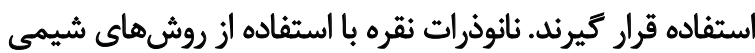

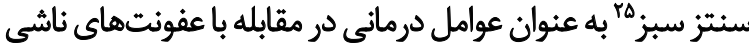

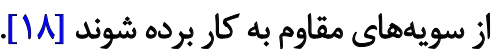

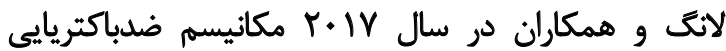

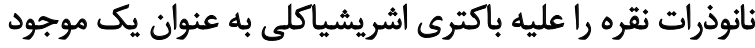

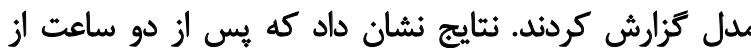

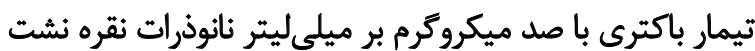

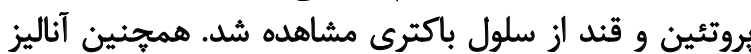

22. Eucalyptus

23. Escárcega-González

24. Bacillus Subtilis

25. Green Synthesize 


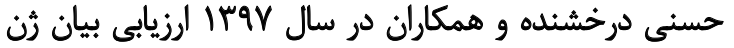

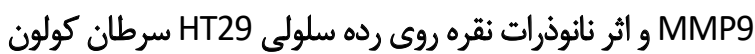

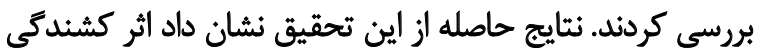

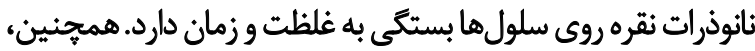

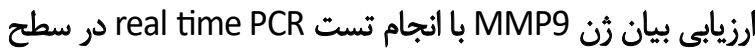

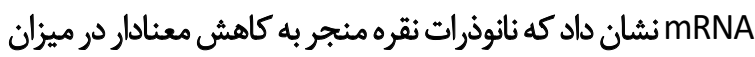

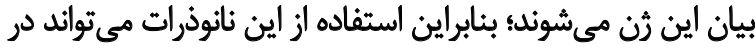

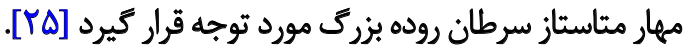

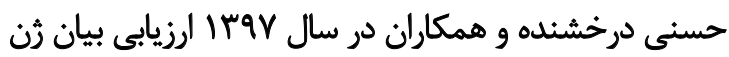

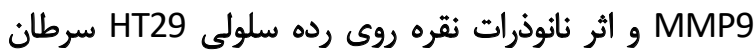

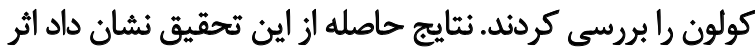

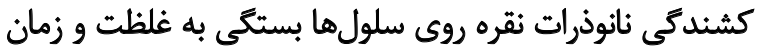

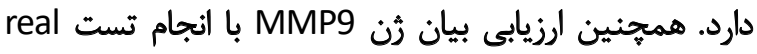

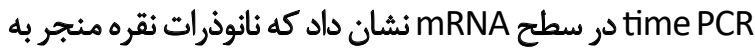

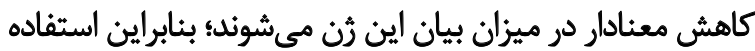

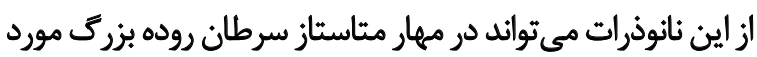

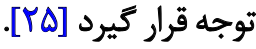

الشدى" در سال 11 +r در مطالعهاى سلولهاى سرطانى

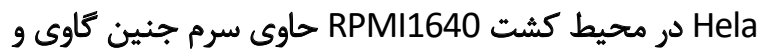

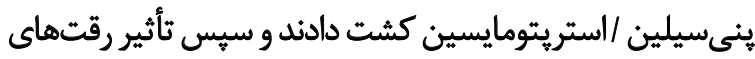

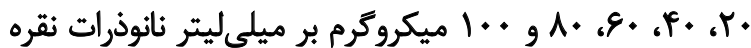

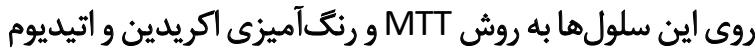

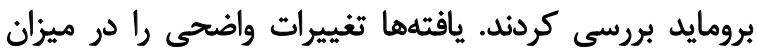

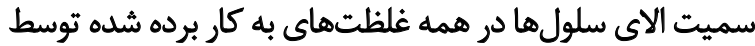

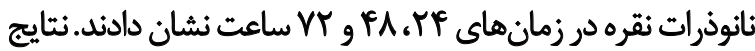

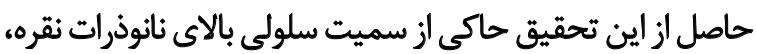

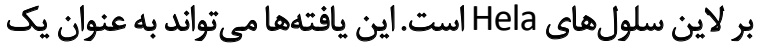

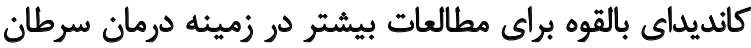

دهانه رحم مورد توجه قرار كيرد [عَائ.

بروسي نأثيرات ناثوذرات نقره بر سلولهاي خوني

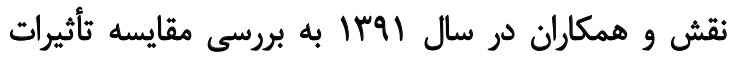

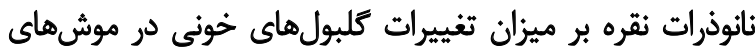

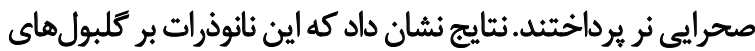

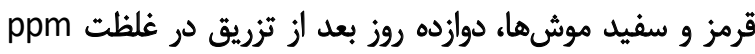

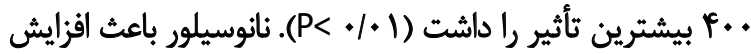

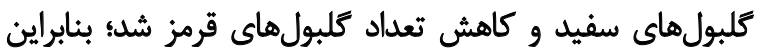

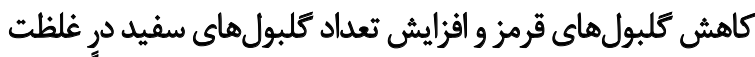

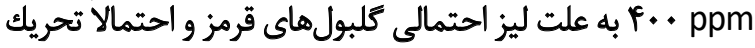

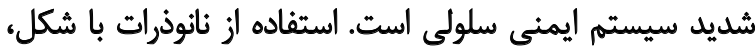

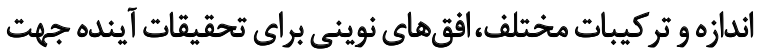

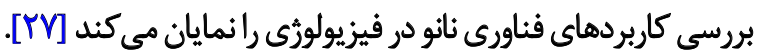

30. Al-Sheddi

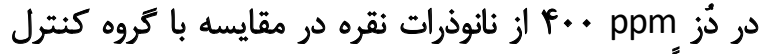

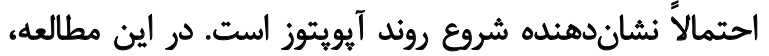

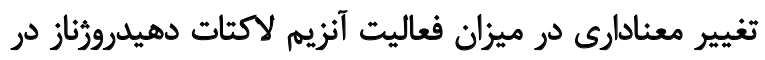

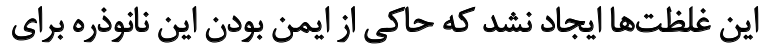

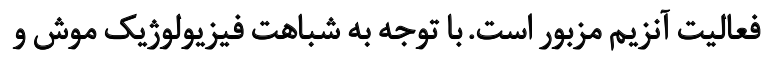

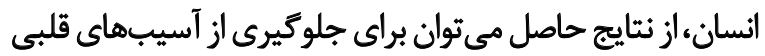

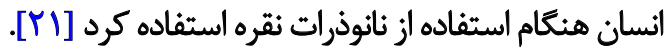

خدادادى و همكاران در سال آجسا به بررسى ثأثير نانوذرات

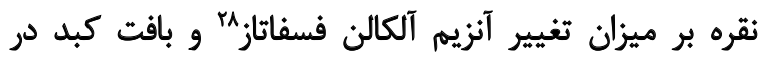

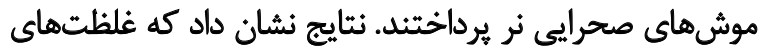

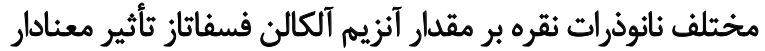

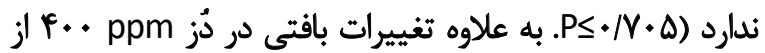

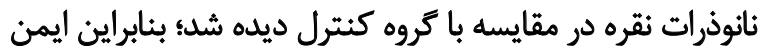

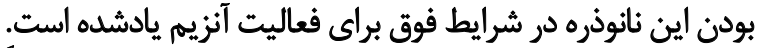

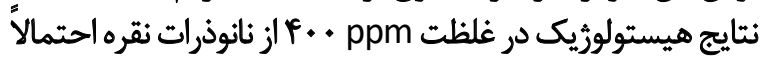

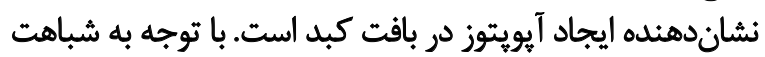

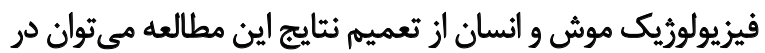
زمينه جلوكيرى از عوارض استفاده از لوازم حاوى نانونقيج انتوه استفاده

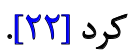

نقش و همكاران در سال |وجا به به بروسى تأثيرات نانوذرات

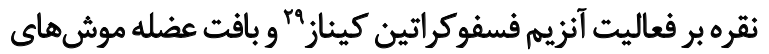

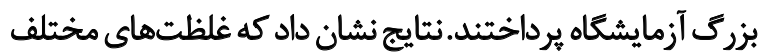

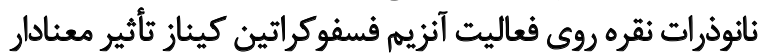

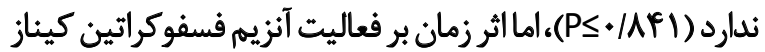

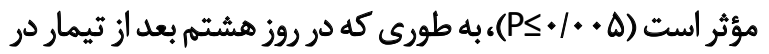

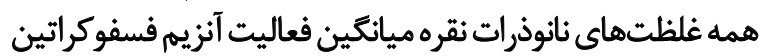

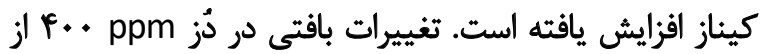

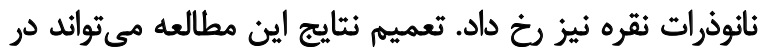

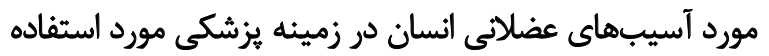
قرار كيرد؛ بنابراين بايد در استفاده از لوازم حاوي نانين بناني نقره احتياط

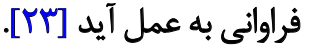

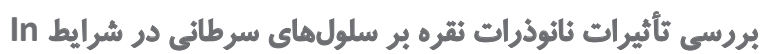
Vitro

خاتمى و همكاران در سال \&9 1 اثر ضدسرطانى نانوذرات نقره

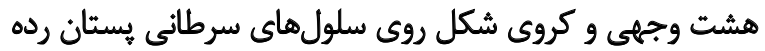

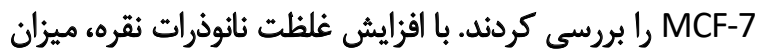

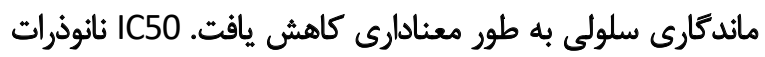

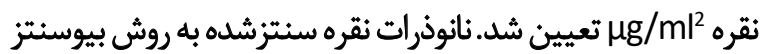

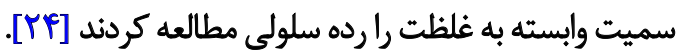

28. Alkalin Phosphatase

29. Phosphocreatine kinase 
عمل انتقال مواد معدنى از سطح ديواره رابه عهيده دارند كه نانومواد

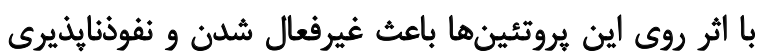

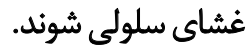

از بين رفتن تراوايى غشا باعث مرك سلولى مي نشود. وجود

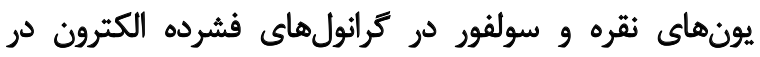

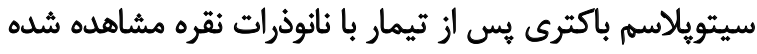

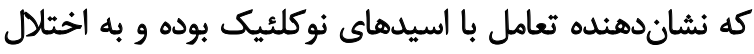

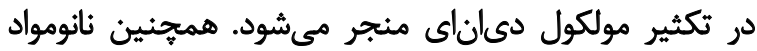

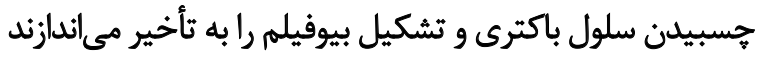

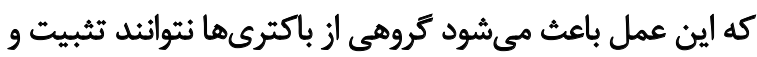

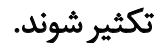
نانوذرات نقره خواص ضدميكروبى روى بيشتر ميكروار كانيسمها بانيا

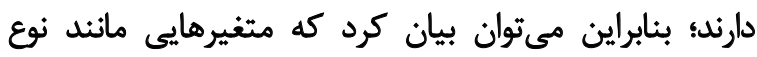

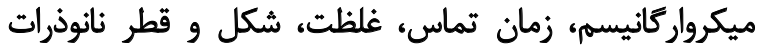

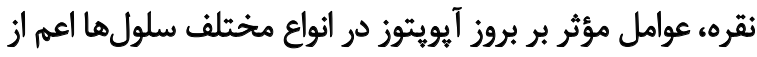

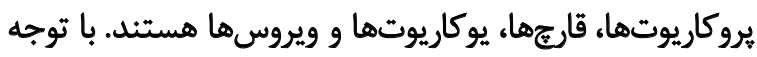

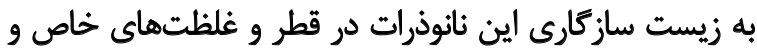

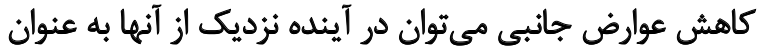

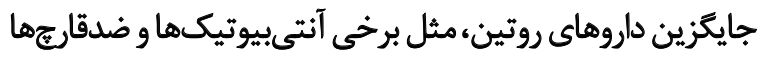

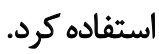

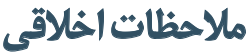

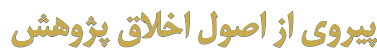

اصول اخلاق نشر در نعارش مقاله رعايت شده است.

$$
\text { Sto sto }
$$

اين مقاله حامى مالى نداشته است.

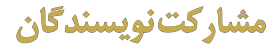

هر دو نويسنده در مرور مطالعات و نكارش مقاله مشاركت

داشتند.

\section{تقارض منافع}

هيجگونه تضاد منافع در يثرهش حاضر وجود ندارد.

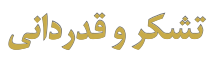

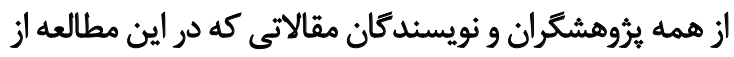

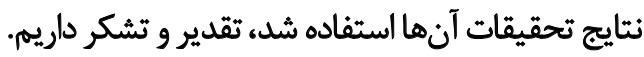

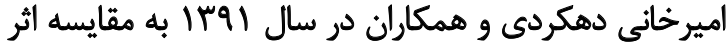

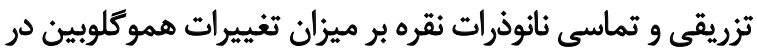

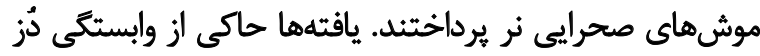

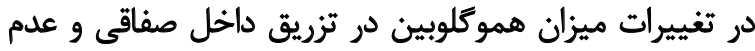

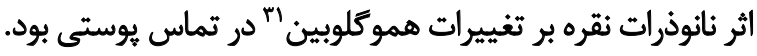

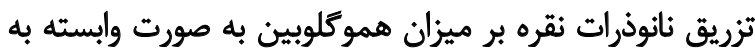

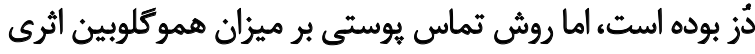

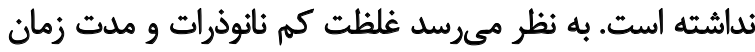

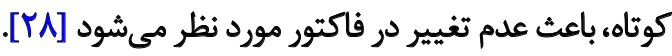

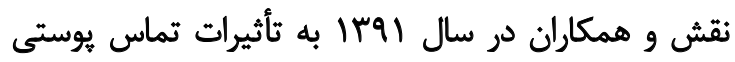

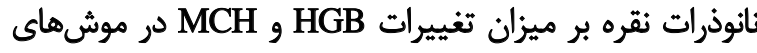

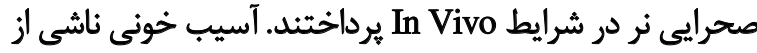

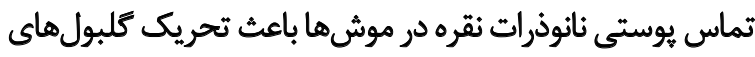

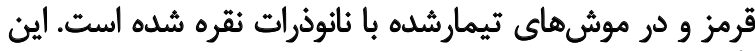

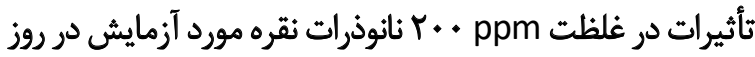

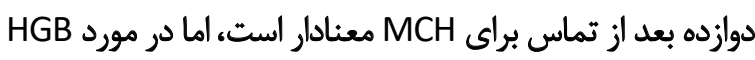

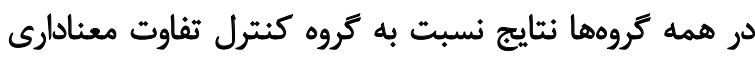

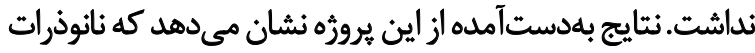

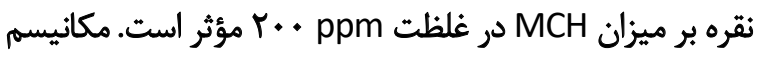

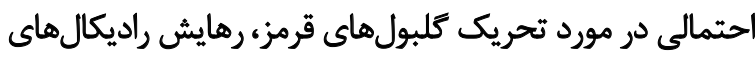

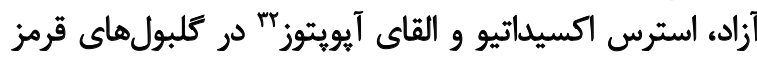

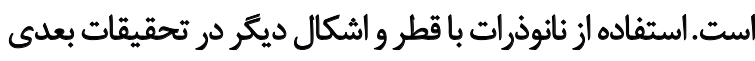

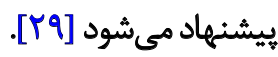

$$
\text { نتيجهَئيرى }
$$

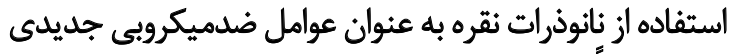

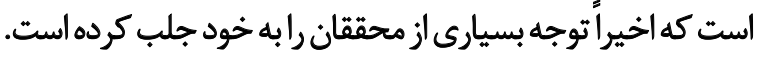

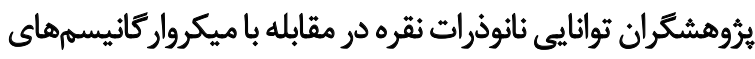

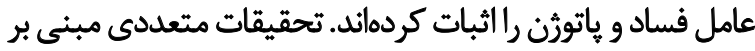

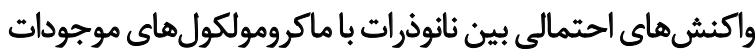

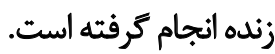

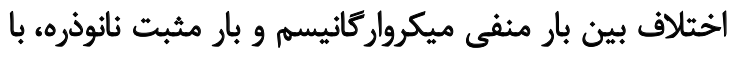

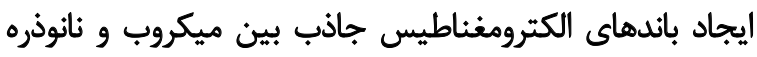

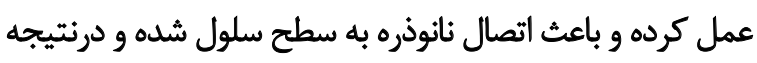

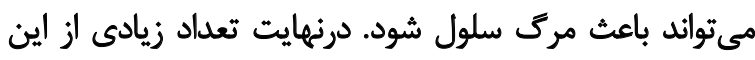

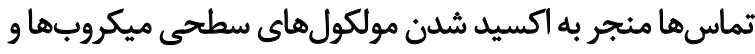

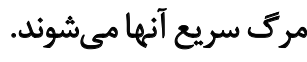
احتمال داده ميشود يونهاى آزادشده از نانومواد با كروههاي

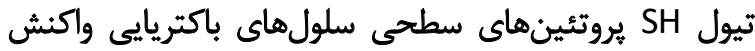

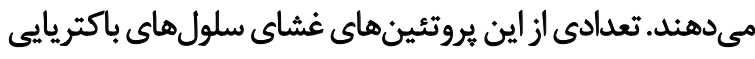

31. Hemoglobin

32. Apoptosis 


\section{References}

[1] Jeevanandam J, Barhoum A, Chan YS, Dufresne A, Danquah MK. Review on nanoparticles and nanostructured materials: History, sources, toxicity and regulations. Beilstein J Nanotechnol. 2018; 9:1050-74. [DOI:10.3762/bjnano.9.98] [PMID] [PMCID]

[2] Singh J, Dutta T, Kim K-H, Rawat M, Samddar P, Kumar P. 'Green'synthesis of metals and their oxide nanoparticles: Applications for environmental remediation. J Nanobiotechnology. 2018; 16(1):84. [DOI:10.1186/ s12951-018-0408-4] [PMID] [PMCID]

[3] Dallas P, Sharma VK, Zboril R. Silver polymeric nanocomposites as advanced antimicrobial agents: Classification, synthetic paths, applications, and perspectives. Adv Colloid Interface Sci. 2011; 166(1-2):11935. [DOI:10.1016/j.cis.2011.05.008] [PMID]

[4] Naghsh N, Safari M, Haj Mehrabi P. [Investigation of the effect of silver nanoparticles on the growth of Escherichia coli bacteria (Persian)] J Qom Univ Med Sci. 2012; 6(2):65-8. https://www.sid.ir/en/journal/ ViewPaper.aspx?ID=260475

[5] Dik DA, Fisher JF, Mobashery S. Cell-wall recycling of the Gram-negative bacteria and the nexus to antibiotic resistance. Chem Rev. 2018; 118(12):5952-84. [DOI:10.1021/acs.chemrev.8b00277] [PMID] [PMCID]

[6] Jarick M, Bertsche U, Stahl M, Schultz D, Methling K, Lalk M, et al. The serine/threonine kinase Stk and the phosphatase Stp regulate cell wall synthesis in Staphylococcus aureus. Sci Rep. 2018; 8(1):13693. [DOI:10.1038/s41598-018-32109-7] [PMID] [PMCID]

[7] Chen S, Quan Y, Yu Y-L, Wang J-H. Graphene quantum dot/silver nanoparticle hybrids with oxidase activities for antibacterial application. ACS Biomater Sci Eng. 2017; 3(3):313-21. [DOI:10.1021/ acsbiomaterials.6b00644] [PMID]

[8] Hu S, Yi T, Huang Z, Liu B, Wang J, Yi X, et al. Etching silver nanoparticles using DNA. Mater Horiz. 2019; 6:155-9. [DOI:10.1039/C8MH01126E]

[9] Sadoon AA, Khadka P, Freeland J, Gundampati RK, Manso R, Ruiz M, et al. Faster diffusive dynamics of histone-like nucleoid structuring proteins in live bacteria caused by silver ions. Appl Environ Microbiol. 2020; 86(6):e02479-19. [DOI:10.1128/AEM.02479-19] [PMID] [PMCID]

[10] Rahimzadeh-Torabi L, Doudi M, Naghsh N, Golshani Z. [Comparing the antifungal effects of gold and silver nanoparticles isolated from patients with vulvovaginal candidiasis in-vitro (Persian)]. Feyz. 2016; 20(4):331-9. http://feyz.kaums.ac.ir/article-1-3130-en.html

[11] Asghari A, Naghsh N, Madani M. [In vitro comparison of antifungal effect of silver nanoparticle on Candida producer of vulvovaginal candidiasis (Persian)]. Iran J Med Microbiol. 2015; 9(3):23-30. https://ijmm.ir/ article-1-270-en.pdf

[12] Naghsh N, Doudi M, Soleymani S, Torkan S. [The synergic effect of alcoholic eucalyptus and nanosilver on colony count of Aspergilus Niger (Persian)]. J Gorgan Univ Med Sci. 2013; 14(4):89-93. http://goums. ac.ir/journal/article-1-1580-en.htm

[13] Naghsh N, Doudi M, Safaeinejad Z. The antifungal activity of silver nanoparticles and fluconazole on aspergillusfumigatus. Med Lab J. 2013; 7(2):7-12. http://mlj.goums.ac.ir/article-1-269-en.html

[14] Kim K-J, Sung WS, Suh BK, Moon S-K, Choi J-S, Kim JG, et al. Antifungal activity and mode of action of silver nano-particles on Candida albicans. Biometals. 2009; 22(2):235-42. [DOI:10.1007/s10534-008-9159-2] [PMID]

[15] Naghsh N, Ghiasian M, Soleymani S, Torkan S. Investigation of Eucalyptus and nanosilver as a new nanomixture for growth inhibition of $\mathrm{E}$. coli. Int J Mol Clin Microbiol. 2012; 2(1):138-40. https://www.sid.ir/en/ journal/ViewPaper.aspx?ID=285316

[16] Doudi M, Naghsh N, Haidarpour A. [The effect of silver nanoparticles on pathogenic gram-negative bacilli resistant to beta-lactam antibiotics (ESBLs) (Persian)]. Med Lab J. 2011; 5(2):44-51. http://mlj.goums.ac.ir/ article-1-171-en.html
[17] Naghsh N, Soleymani S, Torkan S. [Inhibitory effect of alcoholic eucalyptus extract with nanosilver particles on E. coli growth (Persian)]. J Gorgan Univ Med Sci. 2013; 15(2):60-4. http://goums.ac.ir/journal/ article-1-1720-en.html

[18] Escárcega-González CE, Garza-Cervantes JA, Vazquez-Rodríguez A, Montelongo-Peralta LZ, Treviño-Gonzalez MT, Castro EDB, et al. In vivo antimicrobial activity of silver nanoparticles produced via a green chemistry synthesis using Acacia rigidula as a reducing and capping agent. Int J Nanomedicine. 2018; 13:2349-63. [DOI:10.2147/IJN.S160605] [PMID] [PMCID]

[19] Long YM, Hu LG, Yan XT, Zhao XC, Zhou QF, Cai Y, et al. Surface ligand controls silver ion release of nanosilver and its antibacterial activity against Escherichia coli. Int J Nanomedicine. 2017; 12:3193-06. [DOI:10.2147/IJN.S132327] [PMID] [PMCID]

[20] Kim JS, Kuk E, Yu KN, Kim J-H, Park SJ, Lee HJ, et al. Antimicrobial effects of silver nanoparticles. Nanomedicine. 2007; 3(1):95-101. [DOI:10.1016/j.nano.2006.12.001] [PMID]

[21] Kim JS, Kuk E, Yu KN, Kim JH, Park SJ, Lee HJ, et al. Antimicrobial effects of silver nanoparticles. Nanomedicine. 2015; 3(1):95-1. [DOI:10.1016/j. nano.2006.12.001] [PMID]

[22] Naghsh N, Mashayekh AM, Khodadadi S. [Effects of silver nanoparticle on lactate dehydrogenase activity and histological changes of heart tissue in male wistar rats (Persian)]. J Fasa Univ Med Sci. 2013 2(4):303-7. http://jabs.fums.ac.ir/browse.php?a_code=A-10-26 $29 \&$ slc lang $=\mathrm{fa} \& \mathrm{sid}=1$

[23] Khodadadi S, Naghsh N, Mashayekh AM. [Effect of nanosilver on Alkalin phosphatase activity and liver tissue in male rats (Persian)]. Feyz. 2013; 16(7):687-8. http://feyz.kaums.ac.ir/browse.php?a_code=A-10176-967\&slc_lang=en\&sid=1

[24] Naghsh N, Mashayekh A, Khodadadi S. [Effects of silver nanoparticle on phosphocreatine kinase and histological changes of skeletal muscle tissue in male wistar rat (Persian)]. J Mazandaran Univ Med Sci. 2013; 22(97):36-41. http://jmums.mazums.ac.ir/article-1-1763-en.html

[25] Khatami M, Kharazi S, Kishani Farahani Z, Azizi H, Augusto Lima Nobre M. [The anti-cancer effect of octagon and spherical silver nanoparticles on MCF-7 breast cancer cell line (Persian)]. Tehran Univ Med J. 2017; 75(1):72-6. https://tumj.tums.ac.ir/article-1-7996-en.htm

[26] Hassani Derakhshandeh B, Sadat Shandiz S, Abbasi M. [Evaluation of metalloproteinase matrix MMP9 gene expression and effect of silver nanoparticles toward Colon cancer cell line (HT29) (Persian)]. J Cell Tissue. 2018; 9(4):344-52. [DOI:10.29252/JCT.9.4.344]

[27] Al-Sheddi ES, Farshori NN, Al-Oqail MM, Al-Massarani SM, Saquib $\mathrm{Q}$, Wahab $\mathrm{R}$, et al. Anticancer potential of green synthesized silver nanoparticles using extract of Nepeta deflersiana against human cervical cancer cells (HeLA). Bioinorg Chem Appl. 2018; 2018:9390784. [DOI:10.1155/2018/9390784] [PMID] [PMCID]

[28] Naghsh N, Amirkhani-Dehkordi S, Aghababa H. [Investigating nanosilver effects on blood cells counter in male rats (Persian)]. J Shahid Sadoughi Univ Med Sci. 2013; 20(6):716-23. http://jssu.ssu.ac.ir/article1-2282-en.html

[29] Amirkhani Dehkordi Z, Naghsh N, Aqbaba H. [Comparison of injective and contact effect of silver nanoparticles on the rate of hemoglobin changes in male rats (Persian)]. Jorjani Biomed J. 2012; 1(1):38-43. http://goums.ac.ir/jorjanijournal/article-1-200-en.html

[30] Naghsh N, Amirkhani Dehkordi Z, Aghababa H. [Effects of silver nanoparticles contact with skin in $\mathrm{HGB}$ and $\mathrm{MCH}$ changes in male rats in in vivo condition (Persian)]. J Mazandaran Univ Med Sci. 2013; 23(98):11-7. http://jmums.mazums.ac.ir/article-1-1855-en.htm 